\title{
O professor da Educação Especial e o processo de ensino-aprendizagem de alunos com autismo
}

\author{
Andréa Rizzo dos Santos Boettger* \\ Ana Carla Lourenço** \\ Vera Lucia Messias Fialho Capellini***
}

Resumo

O presente trabalho tem como tema o autismo, e buscou verificar como ocorre o processo de ensino-aprendizagem de alunos com autismo em uma escola de educação especial. O Autismo infantil é hoje classificado como um dos "Transtornos Globais do Desenvolvimento (TGD)" e é caracterizado por um comprometimento grave e global em diversas áreas do desenvolvimento, como nas habilidades de interação social recíproca, habilidades de comunicação e presença de estereotipias de comportamento, interesses e atividades. Esse trabalho teve como objetivo identificar a metodologia de ensino utilizada com adolescentes com autismo na educação especial e verificar em que aspectos essa metodologia auxilia no processo de ensino-aprendizagem desses alunos. Para tal, participaram da pesquisa uma professora especialista e três alunos com autismo de uma Escola de Educação Especial localizada no interior do Estado de São Paulo. Para a coleta de dados foram realizadas 19 observações de atividades realizadas pelos alunos com autismo em sala de aula e aplicada uma entrevista semi-estruturada à professora especialista. Os resultados demonstraram que a professora especialista não utiliza nenhuma metodologia de ensino específica para auxiliar no processo de ensinoaprendizagem desses alunos, apesar de existirem algumas metodologias específicas para pessoas com autismo, que são empregadas em escolas de educação especial. Assim, verifica-se uma lacuna no processo de ensino por parte da professora e uma incerteza quanto ao processo de aprendizagem desses alunos com autismo, nessa instituição.

Palavras-chave: Autismo; Educação especial; Ensino.

\footnotetext{
* Professora Doutora da Faculdade de Filosofia e Ciências da Universidade Estadual Paulista "Júlio de Mesquita Filho" (UNESP) - Campus de Marília, São Paulo.

** Atua como Pedagoga em escolas da cidade de Pederneiras, São Paulo, Brasil.

*** Professora Doutora da Faculdade de Ciências da Universidade Estadual Paulista "Júlio de Mesquita Filho" (UNESP) - Campus de Bauru/São Paulo/Brasil.
} 


\title{
Teacher of Special Education and teaching- learning process of students with autism
}

\begin{abstract}
This paper has as subject autism, and sought to verify how the process of teaching and learning of students with autism occurs in a special education school. The Infantile Autism is today sorted as one of the "Global Developmental Disorders (PDD)" and is characterized by a severe and global impairment in several areas of development, such as reciprocal social interaction skills, communication skills and presence of stereotypic behavior, interests and activities. This study aimed to identify the teaching methodology used with adolescents with autism in special education and see in what ways this methodology assists in the teaching and learning of these students. To this end, participated in this study a teacher, expert in this issue, and three students with autism in a Special Education School located within the State of São Paulo. For data collection, 19 observations of activities performed by students with autism in the classroom were conducted and a semi-structured interview with the specialized teacher was applied. The results revealed that the teacher mentioned above does not use any specific teaching methodology to assist in the teaching and learning of these students, although there are some specific methodologies for individuals with autism, which are used in special education schools. Thus, there is a gap in the teaching process on the part of the teacher and an uncertainty about the learning process of these students with autism in this institution.
\end{abstract}

Keywords: Autism; Special education; Teaching.

\section{Escolarização de alunos com autismo}

\section{Introdução}

Autismo é um tema intrigante devido às incertezas de sua causa e aos questionamentos relacionados a ele que não possuem uma resposta exata. Os principais e mais reconhecidos comprometimentos do transtorno autista encontram-se nas áreas da comunicação, comportamento e interação social. Essas dificuldades fazem com que o aluno com autismo tenha certas limitações no processo de ensino-aprendizagem. 
Apesar da tríade de comprometimentos do aluno com autismo, sua escolarização é possível. O aluno com autismo pode ser escolarizado quando Ihe são oferecidas oportunidades para que esse processo ocorra, com um professor que tenha conhecimento sobre os aspectos do autismo e sobre os programas e métodos educacionais mais adequados para ensiná-lo.

Embora se discuta muito sobre o processo de inclusão do aluno com deficiência, ainda há um grande contingente de alunos que frequentam apenas a escola de Educação Especial, como o caso de alunos com autismo. Verificando esta situação, decidiu-se observar e analisar como se dá o processo de escolarização dos alunos com autismo em uma escola de Educação Especial, identificando a rotina diária da sala de aula e a metodologia empregada pelo professor para trabalhar com esse aluno.

De acordo com o Manual Diagnóstico e Estatístico de Transtornos Mentais (DSM-IV-TR, APA, 2002), o autismo infantil é hoje classificado como um dos Transtornos Globais do Desenvolvimento (TGD) e é caracterizado por:

Um comprometimento grave e global em diversas áreas do desenvolvimento: habilidades de interação social recíproca, habilidades de comunicação ou presença de estereotipias de comportamento, interesses e atividades (APA, 2002, p. 98).

Em relação às possíveis causas do transtorno autístico, Zorzetto (2011, p. 23) afirma que, atualmente, as pesquisas mais recentes têm associado o autismo a causas genéticas e que, "até o momento, alterações em mais de 200 genes, distribuídos por quase todos os cromossomos humanos, já foram associados ao autismo".

Ao discorrer sobre aos comprometimentos do autismo, Lorna Wing, na década de 70 , nomeia uma tríade de comprometimentos, à qual foi atribuído o nome de Tríade de Lorna Wing, referindo-se às incapacidades nas três áreas do desenvolvimento das crianças com autismo: incapacidade na comunicação, na interação social e na imaginação (BOSA, 2002).

No que diz respeito ao aspecto educacional da pessoa com autismo, Nilsson (2003) afirma que é preciso usar algumas estratégias visuais, como:

Programação diária individual, um sistema de trabalho individual, atividades adaptadas individualmente para o trabalho independente, obrigações diárias apresentadas 
visualmente, atividades recreativas e atividades motoras, dando suporte adicional com a orientação visual do modo como a sala é mobiliada e usada. (NILSSON, 2003, p. 26)

Atualmente, existem alguns programas educacionais que são mais utilizados e conhecidos para a educação de crianças e adolescentes com autismo, principalmente em escolas de Educação Especial. Entre eles, destaca-se o Programa TEACCH - (Treatmentand Education of Autistic and Related Communication Handicapped Children - SCHOPLER, 1997) e o Currículo Funcional Natural CFN (LEBLANC, 1992).

Em relação aos princípios, objetivos e técnicas educacionais do programa TEACCH, eles se baseiam em: habilidades e interesses, avaliação contínua e cuidadosa, compreensão dos significados, colaboração dos pais, ensino das relações de causa e efeito, ensino de comunicação e independência. Tudo isso é ensinado por meio de: informações visuais, rotinas e previsibilidade, ensino individualizado e ensino de habilidades, em ambientes naturais e com materiais variados (MESIBOV; SHEA, 1998).

Já o Currículo Funcional Natural visa desenvolver habilidades que levem as crianças e os adolescentes a atuar da melhor forma possível dentro de seu ambiente, tornando-os assim independentes e criativos.

Em relação aos princípios norteadores e à metodologia empregada pelo Currículo Funcional Natural, Suplino (2005) aponta que: a pessoa com autismo deve ser tratada como qualquer outra pessoa, que todos podem aprender e que a família deve participar do processo de aprendizagem. $\mathrm{O}$ educador deve ensinar com entusiasmo, o tom de voz e a linguagem usada com o aluno devem ser o mais natural possível, as habilidades do aluno devem ser mais enfatizadas que suas fraquezas, a atenção do aluno deve ser garantida antes de ser dada uma ordem ou fazer um pedido, as ordens dadas devem ser claras e indispensáveis, as ordens não devem ser repetidas mais de duas vezes antes que o aluno processe a informação recebida, deve ser dado tempo suficiente para a resposta do aluno, o educador deve manter-se calmo e interagir como um amigo com seu aluno, elogios devem ser descritivos, ajudas físicas devem ser evitadas de forma a dar ao aluno a oportunidade de fazer sozinho, os interesses do aluno devem ser aproveitados para ensino de novas habilidades.

Diante das considerações até aqui apontadas, este estudo tem por objetivos identificar a metodologia de ensino utilizada com os adolescentes com autismo na Educação Especial e verificar em que aspectos essa metodologia auxilia no processo de ensino-aprendizagem desses alunos. 


\section{Objetivos específicos}

Os objetivos específicos da pesquisa constituem-se em:

- Observar e analisar a rotina diária de uma sala de aula de Educação Especial de alunos com autismo.

- Analisar quais habilidades são mais desenvolvidas e trabalhadas com a utilização da metodologia empregada.

- Verificar se os recursos e a metodologia de ensino utilizada com esses alunos são apropriados, adequados e eficazes.

\section{Metodologia}

Esta é uma pesquisa de cunho descritivo, com abordagem qualitativa, de cujos resultados - após analisados e discutidos - foram extraídas as inferências. Participaram do estudo uma professora de Educação Especial e três alunos com autismo.

A professora é formada em Pedagogia e Letras, possui Especialização em Deficiência Intelectual e tem 40 anos. Trabalha na instituição da pesquisa há dois anos e deu início ao seu trabalho na Educação Especial com alunos com autismo nessa escola.

Quanto aos participantes alunos, serão denominados de Participante1 (P1), Participante 2 (P2) e Participante 3 (P3). Os dados demográficos dos três alunos participantes estão descritos na Tabela 1.

Tabela 1 - Caracterização dos 3 alunos participantes da pesquisa.

\begin{tabular}{llll}
\hline Participantes & 1 & 2 & 3 \\
\hline Idade em anos & 16 & 19 & 15 \\
Gênero & $\mathrm{M}$ & $\mathrm{M}$ & $\mathrm{F}$ \\
$\begin{array}{l}\text { Pontuação no } \\
\text { CARS }\end{array}$ & 33 & 48,5 & 54 \\
$\begin{array}{l}\text { Classificação no } \\
\text { CARS }\end{array}$ & leve/moderado & grave & grave \\
Comunicação & verbal & não verbal & não verbal \\
\hline $\begin{array}{l}\text { Tempo na } \\
\text { instituição }\end{array}$ & 7 anos & 12 anos & 9 anos
\end{tabular}


Os participantes 1 e 2 são do sexo masculino e possuem 16 e 19 anos respectivamente. A participante 3 é do sexo feminino e tem 15 anos. O P1 frequenta a instituição desde 2004, o P2 frequenta desde 1999 e o P3 desde 2002.

O P1 apresenta comunicação verbal, já P2 e o P3 apresentam comunicação não verbal. O participante 1 é capaz de realizar pequenos diálogos, faz pedidos verbais ou por meio de gestos e responde perguntas. $\mathrm{O}$ participante 2 não tem comunicação verbal, porém, entende quando alguém faz algum comentário e é capaz de realizar o que se pede. Ele se comunica por gestos, mas geralmente tenta fazer o que quer de forma independente. Já o participante 3 não possui comunicação verbal nem gestual, entretanto demonstra compreensão em relação ao que é solicitado que ele faça.

Ao ser aplicada a Escala de Avaliação CARS, (Childhood Autism Ratting Scale - SCHOPLER e cols., 1988), que avalia o grau de autismo e o classifica em leve, moderado e severo, foi diagnosticado que P1 apresenta autismo de grau leve a moderado, com pontuação de 33; P2 e P3 apresentam autismo de grau grave, com pontuação de 48,5 e 54 pontos respectivamente. A escala foi aplicada pela própria professora da sala de aula, que recebeu treinamento da para tal aplicação.

A pesquisa realizou-se em uma escola de Educação Especial, em uma cidade de pequeno porte, localizada no interior do estado de São Paulo.

Foram elaborados para a coleta de dados dois roteiros: um roteiro de entrevista semi-estruturada, que foi aplicada à professora e, um roteiro de observação, com itens previamente elencados, para analisar as atividades desenvolvidas pelos alunos em sala de aula.

O roteiro de observação foi baseado no protocolo Code for Instructional Structureand Student Academic Response - Mainstream Version (MS-CISSAR)(CARTA et al. 1988).

O MS-CISSAR analisa as atividades em sala de aula e foi elaborado para estudar a ecologia da sala de aula da Educação Especial e da sala de aula da educação regular. Este instrumento de análise eco-comportamental descreve e avalia a relação entre o comportamento do aluno, a ecologia da sala de aula e o comportamento do professor. 
pesquisa foram:

As categorias observadas e analisadas na realização desta professora;

- atividades: que dizem respeito às tarefas propostas pela

- instruções: referem-se à ordem dada pelo professor: a) para o grupo todo, b) individualmente;

- comportamento do professor: diz respeito à forma como a instrução é aplicada: a) instrução verbal, b) instrução não-verbal;

- comportamento do aluno: inclui: a) comportamento engajado do aluno: ele participa da atividade, b) comportamento atento: o aluno presta atenção no professor, mas não realiza a atividade, c) comportamento não participativo.

Foi aplicado o roteiro de observação baseado no MS-CISSAR para a observação das atividades em sala de aula, mas devido a não autorização de filmagens por parte da direção da escola, a análise foi realizada qualitativamente ao invés de quantitativamente.

\section{Resultados}

As respostas que a professora deu à entrevista em relação aos conhecimentos que ela possuía sobre o autismo antes de iniciar o trabalho com os adolescentes, e sobre as características dos adolescentes com autismo, serão relatadas a seguir:

"Pouco, depois que soube que trabalharia com autistas fui estudar e pesquisar sobre o tema".

"Sim, as principais são movimentos estereotipados, dificuldade na comunicação e linguagem, dificuldade na interação social".

Quanto ao trabalhoque ela poderia desenvolver com os alunos com autismo em sala de aula, a resposta foi:

"Pode-se trabalhar com os autistas jogos pedagógicos e de coordenação motora, brincadeiras com bola e bexiga, desenho livre, giz, artes".

Sobre a metodologia utilizada por ela para trabalhar com os adolescentes com autismo, a professora apontou que: 
"O primeiro passo é fazer com que o autista comece a perceber 0 mundo a sua volta, fazer com que o aluno comece a se socializar. Isto ocorre quando ele compreende que, para cada ação sua, há uma reação do ambiente. Com estes passos futuramente a criança vai conseguindo, pouco a pouco, se expressar".

Nas observações realizadas em sala de aula e no recreio com os 3 alunos com autismo,foi possível perceber que as atividades semanais realizadas por eles foram aulas de: artes, matemática, língua portuguesa, educação física, informática e desenho livre. Os alunos também fazem atividades de coordenação motora, esquema corporal, brincadeiras com brinquedos diversos, percepção e discriminação de figuras. Eles também vão ao parque, tomam o lanche, fazem hidroterapia, aprendem sobre higiene pessoal, assistem vídeo e são atendidos pela psicóloga e terapeuta ocupacional da escola.

As atividades de Artes envolviam colagens, pinturas e desenhos. Os alunos elaboraram um cartão para o Dia das Mães; construíram uma pequena maquete; desenharam uma árvore; fizeram um rosto humano com EVA e realizaram pinturas diversas.

Durante a realização dessas atividades, a professora ensinava conceitos aos alunos como: a forma de segurar um lápis, treinava coordenação motora fina,cores, percepção e discriminação de imagens a partir das figuras que eles pintavam. Também foi trabalhado com os alunos o corpo humano a partir da elaboração de um rosto humano, ensinando o esquema corporal.

Na aula de matemática, as atividades realizadas com os alunos eram quase sempre relacionadas à contagem, ou a jogos matemáticos. Eles contavam os dedos, os lápis, os brinquedos, as bolachas. A professora utilizava objetos ou acontecimentos do cotidiano da sala de aula para introduzir os números a eles.

Em relação aos jogos, estes eram sempre sobre encaixar formas geométricas, tais como: triângulo, círculo, quadrado e/ou retângulo em uma prancha de madeira.

A disciplina de Língua portuguesa consistia em apresentar e mostrar as letras dos nomes de cada aluno. As letras eram escritas pela professora na lousa, mas os alunos não copiavam as letras no caderno. 
Na Educação Físicas aulas ministradas pelo professor aconteciam às quintas-feiras. As aulasobservadas envolveram atividades em um pulapula e caminhada. Na atividade de caminhada, a professora da sala de aula participou. Durante a caminhada, o professor de Educação Física trabalhou conceitos como: rápido e devagar, na hora que acelerava ou diminuía a velocidade da caminhada.

As aulas de informática eram realizadas às segundas-feiras e ministradas por uma professora de Informática. As aulas observadas consistiram em mostrar aos alunos vídeos no Youtube; estes eram de músicas infantis como Xuxa, Galinha Pintadinha e Patati Patatá.

No desenho livre: os alunos ficaram livres para rabiscar ou desenhar o que quisessem em uma folha de papel. A professora aproveitava o momento para lhes mostrar diferentes cores e para ensiná-los a segurar o lápis.

Coordenação motora: para desenvolver e aperfeiçoar a coordenação motora, os alunos utilizavam jogos e brinquedos próprios, como: brinquedos de rosquear (pranchas com partes de garrafa Pet e de produtos de limpeza colados) e brinquedos de manipulação infantil (que estimulam coordenação motora, discriminação visual e auditiva e preensão). Outra forma de desenvolver a coordenação motora consistia em o aluno fazer treinos de traçoshorizontais, verticais e círculos.

$\mathrm{Na}$ atividade de esquema corporal, a professora mostrou aos alunos partes do corpo, primeiramente, ela, por meio de uma boneca, apresentouIhes os braços, pernas, mãos, pés e a barriga da boneca. Após, apresentava, em cada aluno, as partes do próprio corpo como os braços, pernas, pés, mãos e barriga e falava como chamava cada uma dessas partes. Em algumas atividades a professora também utiliza um espelho para que eles tenham o autorreconhecimento de sua imagem corporal.

Brincadeiras e Brinquedos diversos: as brincadeiras realizadas com os alunos foram com bexiga e bola e consistiam em jogar e agarrar. Com brinquedos, eram disponibilizados aos alunos bonecas, ursos de pelúcia, carrinhos e brinquedo de borracha para morder. Na hora da brincadeira com os brinquedos os alunos eram livres, a atividade não era direcionada.

Para a percepção e discriminação de figuras, eram apresentadas aos alunos, eram mostradas figuras de livros infantis para desenvolver a percepção e a discriminação de imagens. Foram mostradas imagens de animais, árvores, flores e objetos em geral. 
Na hora do parque a atividade era livre nos brinquedos como (balanço, escorregador e gira-gira). Eles também brincavam na areia.

Na hora do lanche, que era feito diariamente no refeitório; cada aluno tinha seu lugar determinado para realizar as refeições. água.

A Hidroterapia era o momento para relaxamento e caminhada na

Higiene pessoal: envolvia escovação dos dentes e lavagem das mãos após o lanche e banho dirigido, que ocorria após o parque ou quando necessário. Esta atividade era realizada por uma auxiliar da instituição.

As aulas na sala de vídeo consistiam em passar os vídeos da Xuxa e do Patati Patatá, porém apenas um aluno demonstrava interesse nos vídeos, os demais não prestavam atenção.

Atendimento com psicóloga e terapeuta ocupacional (TO): os atendimentos eram realizados às segundas-feiras. Foi possível observar apenas o atendimento da TO. Em um dia, a TO trabalhou com os alunos Atividades de vida diária (especificamente vestuário - atividades comzíper e diversos botões). Em outro dia, a TO montou, juntamente com os alunos, quebra-cabeças de animais, estimulando discriminação e percepção de imagens a partir de figuras em peças de um jogo.

Percebeu-se, também, que a professora normalmente trabalhava individualmente com cada aluno e que as instruções referentes às atividades não eram visuais, mas sempre verbais. Além disso, notou-se que era oferecido um número maior de atividades para o Participante 1 , entretanto, o Participante 3 permanecia a maior parte do tempo sem atividades.

\section{Discussão}

Diante das respostas apresentadas pela professora, percebeuse que, antes de ter contato com pessoas com autismo, ela não possuía conhecimento sobre o autismo e, o pouco que adquiriu foi mediante pesquisas individuais, realizadas por conta própria. Pode-se inferir que isto representa um despreparo tanto da escola de Educação Especial quanto da professora, que foi contratada para trabalhar com alunos com autismo, sem ter o conhecimento sobre as características dessa população. 
Ao ser questionado sobre as características da pessoa com autismo, a professora demorou a dar a resposta, demonstrando ter o conhecimento do senso comum.

Quanto à metodologia de ensino empregada para trabalhar com alunos com autismo, a professora não disse, que conteúdos ou conhecimentos específicos podem ser trabalhados com esses alunos, demonstrando não haver uma metodologia específica usada por ela. Entretanto, há metodologias específicas para serem utilizadas no processo de escolarização do aluno com autismo, como o TEACCH (SCHOPLER, 1997) ou o Currículo Funcional Natural (LEBLANC, 1992) dentre outros.

Durante as 19 observações, verificou-se que os alunos realizaram algumas atividades, porém, nessas atividades, conteúdos escolares, atividades que preparem os alunos para a vida, para o trabalho, que estimulem a comunicação e a linguagem e que os tornem independentes praticamente não foram trabalhadas ou, quando o foram, não foi dada tanta atenção.

Discutindo-se cada uma das atividades, têm-se o que segue:

Nas atividades de Artes, o foco era em colagens e pinturas, tendo em muitas atividades o propósito de treinar coordenação motora ao pintar e colar; não havia conhecimento sistematizado sobre o que são Artes e quais são os meios de representações artísticas.

Nas atividades de Matemática, o conhecimento sistematizado e o conteúdo escolar receberam um pouco mais de atenção do que nas atividades de Artes. A professora trabalhou com atividades de contagem numérica, porém, ao fazer essa contagem, os números em si nunca foram apresentados aos alunos; a utilidade dos numerais nunca foi ensinada e os números eram apenas verbalizados pela professora ao contar objetos.

Outros conteúdos escolares trabalhados com os alunos foram figuras geométricas e a relação entre espaço forma, por meio de brinquedos com formas geométricas que consistia em encaixá-las nos lugares correspondentes. No entanto, não foi feita uma introdução com os alunos sobre o que é forma geométrica, a relação de formas geométricas com o cotidiano, o que era necessário já que conceitos matemáticos são muito abstratos para os alunos com autismo.

No conteúdo de espaço e forma, a única forma de desenvolvê-lo foi mediante o encaixe de formas geométricas nos espaços correspondentes; 
nessa atividade, percebeu-se que os alunos não foram estimulados a se localizar no espaço, a ver a relação de outros objetos com o espaço ao seu redor. Tudo o que foi trabalhado em relação a figuras geométricas, espaço e forma e números foi de maneira restrita e nada funcional.

Apesar de a professora ter trabalhado com os conteúdos escolares de Matemática de forma superficial e sem se aprofundar em tema algum, podese afirmar que o aluno com autismo tem capacidade de aprender Matemática, de aprender a calcular. Para exemplificar essa afirmação, recorre-se a uma pesquisa feita por Gomes (2007), em que foi analisado o processo de aprendizagem de uma aluna com autismo de grau leve/moderado, em adição e subtração. Segundo Gomes (2007), o ensinamento de adição e subtração partiu de habilidades mais simples para as mais complexas:

1) adição com números de dois ou mais dígitos; 2 ) adição com número a ser elevado; 3) subtração simples, com números de apenas um dígito; 4) subtração com números de dois ou mais dígitos; 5) discriminação entre tarefas de adição e subtração; 6) subtração com números menores que dez e 7) subtração com números entre onze e dezoito (maiores que dez). (GOMES, 2007, p. 351)

A autora acrescenta que os resultados obtidos foram bons, garantindo a aprendizagem das habilidades ensinadas.

$\mathrm{Na}$ única atividade de língua portuguesa que foi desenvolvida com os alunos, o conteúdo escolar trabalhado restringiu-se a letras. A professora escreveu na lousa e ensinou as letras iniciais dos nomes, mas não foi ensinado que as letras formam palavras e textos e que servem também para comunicação; não foi ensinado que as letras representam os sons da fala (fonemas). Enfim, trabalhou-se apenas a forma das letras.

Em atividades de Educação Física, os alunos foram apenas ao pula-pula e fizeram caminhadas. Durante a caminhada, foi apenas trabalhado o conceito de rápido e devagar; não houve outras brincadeiras ou jogos que desenvolvessem outras habilidades.

Foram trabalhadas noções de esquema corporal com os alunos, mas não focadas em conteúdos de Ciências; era apenas realizada a nomeação das partes do corpo. 
A coordenação motora foi estimulada em forma de brinquedos, ao fazer traços e círculos na lousa, nas atividades de Artes (pintar desenhos) e de desenho livre.

A discriminação e a percepção de imagens também foram trabalhadas por intermédio de imagens de livros infantis. Esse mesmo trabalho foi realizado pela TO, durante seu atendimento, com atividades de vida diária (apenas vestuário).

Em atividades com vídeos musicais os alunos ficavam livres para assistir ou não, não havendo interferência da professora.

Em atividades no parque ou com brinquedos diversos, os alunos também ficaram livres, podendo brincar com o que desejassem.

Nas atividades de higiene pessoal a auxiliar estava sempre fazendo por eles. Na maioria das vezes, eles não realizam essas atividades sozinhos, sempre com auxílio.

Pôde-se verificar, durante as observações realizadas, que atividades educativas com conteúdo escolar, que ensinem conceitos, que estimulem a comunicação e a linguagem, que preparem os alunos para a vida, para o trabalho e para serem independentes, quase não foram ensinadas e, quando oferecidas, foi de forma superficial. Entretanto, é importante frisar que, na educação dos alunos com autismo, atividades assim podem e devem ser trabalhadas. Para fundamentar a importância da realização dessas atividades, que desenvolvam os aspectos referidos acima, são citados alguns autores e autoras que discorrem sobre o assunto.

Riviéri (1995) ressalta que, para cada uma das atividades educativas, há objetivos, incluindo conteúdos específicos que devem ser trabalhados com alunos que apresentam autismo. Afirma, ainda, que o aluno com autismo é capaz de realizar as mesmas atividades educativas que os outros alunos, as quais tenham os mesmos objetivos gerais. Assim, fundamentando-se no enfoque evolutivo, os conteúdos a serem trabalhados com alunos com autismo devem envolver uma sequência baseada nos dados existentes sobre o desenvolvimento normal da criança, percorrendo o passo a passo, o mais semelhante possível ao que ocorre na evolução normal.

Riviéri (1995) ensina que é importante desenvolver atividades que estimulem a linguagem e a comunicação. Essas atividades são tão 
fundamentais que Mesibov e Shea (1998) as apresentam comoum dos objetivos do Programa TEACCH.

Já sobre as atividades que preparam os alunos com autismo para a vida, para o trabalho e para independência, Nilsson (2003) destaca que os alunos devem realizar as que estimulem exercícios funcionais para a vida cotidiana e para o trabalho, a fim de torná-los realmente independentes.

Suplino (2005) confirma a importância dessas atividades, baseandose no Currículo Funcional Natural. Segundo essa autora "o objetivo do CFN é tornar os alunos independentes e produtivos, tendo como alvo inseri-los, um dia, no mercado de trabalho" (SUPLINO, 2005, p. 35). Isto vem a ocorrer se eles aprenderem desde as habilidades mais básicas até as habilidades escolares.

Percebeu-se que a professora não trabalhava com atividades que exigissem mais concentração e habilidades dos alunos, pois ficaram bastante tempo livres e sem atividades, principalmente a Participante 3, que possui o grau mais severo de autismo. Isto foge ao que Suplino (2005) postula como um dos princípios norteadores do Currículo Funcional Natural: todos podem aprender.

Sobre ametodologia de ensino utilizada pela professora, podese dizerque, não se observou nada de específico, uma vez que não havia uma rotina estabelecida. A única rotina era em relação às aulas de Artes, de Hidroterapia, do atendimento com psicóloga e TO, de Informática e de Educação Física, pois são atividades realizadas com outros profissionais e com horário determinados; porém, mesmo essas atividades, nem sempre eram realizadas.

Na sala de aula, apesar de a professora ter um cronograma de atividades diárias, este não era seguido.

Paraoalunocomautismo, seguirumarotinaémuitoimportanteparaque ele consiga organizar-se no ambiente e aprender, conforme salientam Mesibov e Shea (1998). Segundo esses autores, o ensino individualizado é uma das técnicas utilizadas pelo Programa TEACCH, o qual foi empregado pela professora, mas não de forma sistematizada.

Foi possível perceber, também quenão eram passadas aos alunos instruções ou informações visuais referentes às atividades que iriam realizar 
no dia. De acordo com Mesibov e Shea (1998), essas instruçõesvisuaissãoe xtremamenteimportantesparaque os alunoscomautismo consigam aprender.

Concluindo-se a análise do trabalho com as atividades educativas, pôde-se perceberque a formacomo elas eram propostas aos alunos, não os preparavam para serem independentes, para a rotina da vida cotidiana, poisnão eram atividadesfuncionais. Foram realizadas algumas atividades acadêmicas e algumas atividades de vidadiária, porém, poucas, sendo que a maioria não era para estimulá-los ou ensiná-los a agir de forma independente, já que, na maioria das vezes, outros faziam por eles.

\section{Referências}

AMERICAN PSYCHIATRIC ASSOCIATION. Manual diagnóstico e estatístico de transtornos mentais: DSM-IV-TR. 4. ed. Porto Alegre: Artmed, 2002.

BOSA, C. Autismo: atuais interpretações para antigas observações. In: BAPTISTA, C. R.; BOSA, C. (Col.). Autismo e educação: reflexões e propostas de intervenção. Porto Alegre: Artmed, 2002 pp. 29-35.

CARTA, J. J. et al. Code for instructional structure and student academic response: mainstream version (MS-CISSAR). Em LOGAN, K. R.; E. B. KEEFE. A comparison of instructional context, teacher behavior, and engage behavior for students with severe disabilities in general education and selfcontained elementary classrooms. The Journal of the Association for Person with Severe Disabilities, 1997, n. 22, pp. 16-27.

GOMES, C. G. S. Autismo e ensino de habilidades acadêmicas: adição e subtração. Revista Brasileira de Educação Especial. Marília, 2007, v.13 (3), pp. 345-364.

GUPTA, A. R.; STATE, M. W. Autismo: genética. Revista Brasileira de Psiquiatria. São Paulo, 2006 v. 1 (28), pp. 29-38.

LEBLANC, J. M. El CurriculumFuncional en la educación de la persona con retardo mental. Trabalho apresentado na ASPANDEM, Mallagra, España, 1992.

Currículum funcional/natural para la vida: definición y desarrollo histórico. Centro de Educación Especial. Ann Sullivan, Peru, 1998. 
MESIBOV, G. B.; SHEA, V. The culture of autism: from theoretical understanding to educational practice. Division TEACCH. Supplemental Reading in Autism for TEACCH Trainning. The University of North Carolina at Chapel Hill. Manuscrito não publicado, 1998.

NILSSON, I. A educação de pessoas com desordens do espectro autístico e dificuldades semelhantes de aprendizagem.Temas sobre desenvolvimento, São Paulo, 2003, maio-junho, v. 12(68), p. 5-45.

RIVIĖRE, A. O desenvolvimento e a educação de criançasautistas. Em COLL, C.; PALACIOS, J.; MARCHESI, A. (Org.). Desenvolvimentopsicológico e educação: necessidades educativas especiais e aprendizagem escolar. Porto Alegre: Artes Médicas, v. 3, 1995.

RITVO, E. R.; ORNITZ, E. M. Medical assesment. Em RITVO, E. R. Autism: diagnosis, current research and management.New York: Spectrum, 1976

SCHOPLER, E. Implementation of TEACCH philosophy. Em COHEN, D. J.; VOLKMAR F. R. (Ed.). Handbook of autism and pervasive developmental disorders. 2. ed. New York: John Wiley \&Sons, 1997, p. 767-795.

.; REICHLER, R. J.; RENNER, B. The Childhood Autism Rating Scale (CARS). Western Psycological Services, Los Angeles, CA, 1998.

SCHWARTZMAN, J. S.; ASSUMPÇÃO J. R., F. B. (Col.). Autismoinfantil. São Paulo: Memnon, 1995.

SUPLINO, M. H. F. Currículo funcional natural:guia prático para e educação na área de autismo e deficiência mental. Brasília: CORDE, 2005.

WING, L. A educação de crianças autistas. guia para professores e pais. São Paulo: Paidós Educador, 1971.

ZORZETTO, R. O cérebro no autista.Pesquisa FAPESP, São Paulo, 2011, n. 184, p.16-23.

\section{Correspondência}

Andréa Rizzo dos Santos Boettger - Universidade Estadual Paulista - Campus de Marília, Faculdade de Filosofia e Ciências. Av. Hygino Muzzi Filho, 737, caixa postal 181, Campus Universitário, CEP 17525-000 - Marilia, São Paulo.

E-mail: andreagiar@marilia.unesp.br 